\title{
Prevalence and Clinical Implications of Orthostatic Hypotension in Elderly Inpatients
}

Michela Tibaldi ${ }^{*}$, Alessia Brescianini, Irene Sciarrillo, Massimiliano Massaia and Mario Bo

SC Geriatria e Malattie Metaboliche dell'Osso, AO Città della Salute e della Scienza di Torino, Torino - Italy

${ }^{*}$ Corresponding author: Michela Tibaldi, SC Geriatria e Malattie Metaboliche dell'Osso, AO Città della Salute e della Scienza di Torino, Presidio Molinette, C.so Bramante 88, 10100 Torino - Italy; E-mail: michela_tibaldi@yahoo.com

Received date: April 25, 2014; Accepted date: June 15, 2014; Published date: June 25, 2014

Copyright: () 2014 Tibaldi M. This is an open-access article distributed under the terms of the Creative Commons Attribution License, which permits unrestricted use, distribution, and reproduction in any medium, provided the original author and source are credited.

\begin{abstract}
Background: Prevalence of orthostatic hypotension $(\mathrm{OH})$ has been investigated in many studies, mainly on selected samples of subjects. We aimed to assess the prevalence of $\mathrm{OH}$ and its association with incidence of adverse events among older medical inpatients.
\end{abstract}

Methods: $\mathrm{OH}$ was evaluated according to current guidelines at admission and at discharge among older medical inpatients admitted to a Geriatric acute ward of an university-teaching hospital. A comprehensive clinical (CIRS, Cumulative IIIness Rating Scale), functional (ADL, Activities of Daily Living; IADL, Instrumental Activities of Daily Living Scale, TUG, Timed Up and Go) and cognitive (SPMSQ, Short Portable Mental Status Questionnaire) evaluation was performed. Length of stay-in and adverse events (death, institutionalization, falls, syncope, posttraumatic fractures, cardiovascular events) were evaluated at discharge and at 6 months.

Results: Among 343 patients admitted, 195 (mean age 80.1 47.2 ) were enrolled. Prevalence of $\mathrm{OH}$ at admission was 52.3\%; patients with $\mathrm{OH}$ had higher systolic and diastolic blood pressure values $(p=0.001$ both) and lower heart rate $(p=0.02)$ than patients without $\mathrm{OH}$. Although several conditions were associated with presence of $\mathrm{OH}$, only history of neurological and coronary artery disease were slightly independently associated with $\mathrm{OH}(\mathrm{p}=0.03$ and $p=0.02$, respectively). Prevalence of $\mathrm{OH}$ at discharge was $49 \%$. $\mathrm{OH}$ was not significantly associated with any adverse event, nor during the hospital stay nor after discharge.

Conclusion: $\mathrm{OH}$ is extremely common among elderly inpatients, but it was not associated with adverse events. Our results question the utility of routinely screening older medical inpatients for $\mathrm{OH}$.

Keywords: Orthostatic hypotension; Elderly; Inpatients; Coronary artery disease

\section{Introduction}

Orthostatic hypotension $(\mathrm{OH})$ is defined as a decline in systolic or diastolic blood pressure of at least 20 and $10 \mathrm{mmHg}$ respectively, while standing up from a lying position within 3 minutes of observation [1]. Its prevalence among home-dwelling elderly has been reported to vary from 6 to 30\% [2-11], reflecting differences in samples studied and measurements protocols [12]. Similarly, among nursing-home residents a wide range of prevalence has been reported (18-50\%) $[13,14]$. Few studies focused their attention on elderly inpatients: Shibao et al, analyzing discharge data from the American Nationwide Inpatient Sample, found that among patients over 75 years the incidence of $\mathrm{OH}$-related hospitalizations was 233 on 100000 [15], but the prevalence seems to be much higher in acute geriatric medical wards [16]. In a retrospective study conducted in a veterans' geriatric clinic $\mathrm{OH}$ affected up to $55 \%$ of the men admitted to the hospital [17]. Similar findings were reported in one other small-cohort study [18].

Despite the high prevalence of $\mathrm{OH}$ reported in these studies, there are contrasting evidences on clinical implications of $\mathrm{OH}$ among elderly subjects. Although some studies demonstrated that $\mathrm{OH}$ is associated with adverse events, including myocardial infarction, coronary artery disease, incident heart failure, recurrent falls, overall and cardiovascular death $[2,4,10,11,19-22]$, several other studies have reported negative results $[4,6,9,10,19,23-25]$. However, most of these studies have been performed on selected samples of subjects, mainly on community-dwelling hypertensive or diabetic individuals with few other co morbidities. To the best of our knowledge, there are very few studies [16-18,26,27] investigating prevalence and clinical implications of $\mathrm{OH}$ among elderly contemporary hospitalized patients. "We hypothesized that, in such a frail and vulnerable sample of patients, there should be a high prevalence of $\mathrm{OH}$," thereby consenting to evaluate whether this condition is consistently associated with adverse events during the hospital stay and at short term after discharge. In the present study we aimed primarily to evaluate the prevalence of, and the clinical conditions associated with, $\mathrm{OH}$ in a sample of elderly medical inpatients admitted to a Geriatric Unit of a Universityteaching hospital, and secondly to investigate whether $\mathrm{OH}$ was associated with length of stay and with greater incidence of adverse events (including syncope, falls, post-traumatic fractures, rehospitalization, institutionalization, death and cardiovascular events) during the hospital stay and at six months after discharge.

\section{Methods}

During the period December 2011-March 2012, patients aged $\geq 65$ years consecutively attending the Geriatric Acute Ward of San 
Giovanni Battista-Molinette University Hospital in Turin (Italy) were recruited for this study. Subjects were asked to give an informed consent before to join the study. We excluded terminal patients and those unable to reach and keep the standing position on their own.

Prevalence of $\mathrm{OH}$ was investigated at admission and at discharge. Blood pressure (BP) measurement was made according to the current European guidelines for arterial hypertension [28] using a manual mercury sphygmomanometer with an appropriate sized cuff. BP was recorded in a lying position after 5 minutes of bed rest, then after 30 seconds, 1 and 3 minutes of standing. We extended the length of time test to 5 minutes in order to find delayed forms following the most recent indications for the $\mathrm{OH}$ diagnosis [29]. BP measurements were made during the day at least thirty minutes after meals. The cardiovascular response was investigated by recording the peripheral heart rate whilst supine and upright as suggested by the current European $\mathrm{OH}$ guidelines [30].

For each patient demographic variables (age/gender) and medical history of congestive heart failure, coronary artery disease (CAD), hypertension, arrhythmia, valvular disease, neurological disease and diabetes were considered at admission. We recorded both the overall number of medications and the main drugs categories such as antihypertensive (calcium channel antagonists, angiotensin receptor blockers, angiotensin converting enzyme inhibitors, beta or alpha blockers, diuretics), analgesics/opioids, benzodiazepine, neuroleptics, atypical antipsychotics and anticholinergics. The following measures were obtained: height (meters), weight (kilograms), Body Mass Index [BMI, calculated according to the formula weight (kilograms)/height (square meters)]. Previous falls and syncope were investigated. Indexes of co morbidity and global physical health (CIRS, Cumulative Illness Rating Scale) [31], cognitive status (SPMSQ, Short Portable Mental Status Questionnaire) [32], functional autonomy (ADL, Activities of Daily Living; IADL, Instrumental Activities of Daily Living Scale) [33,34], and mobility (Timed Up and Go) [35] were carefully assessed in each patient. Length of stay-in (measured in days), survival and adverse events (including syncope, falls, post-traumatic fractures, rehospitalization, institutionalization, death and cardiovascular events) were recorded at discharge and after 6 months through telephone interview. For those patients we have not been able to contact after discharge we addressed to the Demographical Services of residence Communes to verify their alive status: these subjects were included into the survival analysis but excluded from the other ones.

\section{Statistical Analysis}

The Statistical analysis was performed via the Software SPSS 19.0 for Windows. For the continuous variables the mean and the standard deviation have been evaluated; for the Boolean variables percentage has been calculated. The Boolean variables have been analyzed through the $\chi^{2}$ test; the continuous variables by using the t-test for paired data. Stepwise multiple linear regression analysis was performed introducing variables achieving the level of significance at the simple analysis. The survivals curves have been evaluated using the Kaplan-Meyer method with Log Rank of significance.

\section{Results}

During the period of observation 343 patients were admitted to our ward; 148 patients were excluded: 118 were unable to stand or keep the upright position, 26 were terminal patients, and 4 were in an advanced stage of dementia, with low compliance with the operators. The final sample studied was therefore composed by 195 subjects (101 women and 94 men, mean age $80.1 \pm 7.2$ years). Because of prevalence of $\mathrm{OH}$ did not change at the 5 -minute test, results will be referred to the standard 3-minute test. In the overall sample only 44 patients were steadily $\mathrm{OH}$ free both at entry and at discharge. The main clinical characteristics of the patients according to the presence of $\mathrm{OH}$ are shown in Table 1.

\begin{tabular}{|c|c|c|c|}
\hline $\begin{array}{l}\text { Characteristics and } \\
\text { Co morbidities }\end{array}$ & $\begin{array}{l}\text { With } \mathrm{OH} \quad(n=102) \\
\text { Mean } \pm \mathrm{SD} / \%^{+}\end{array}$ & $\begin{array}{l}\text { Without } \mathrm{OH}(n=93) \\
\text { Mean } \pm \mathrm{SD} / \%\end{array}$ & P-Value \\
\hline Age & $79.7(7.5)$ & $80.6(6.9)$ & 0.35 \\
\hline $\mathrm{BMI}\left(\mathrm{Kg} / \mathrm{m}^{2}\right)$ & $24.7(5.6)$ & $24.9(5.0)$ & 0.86 \\
\hline Gender (male/female) & $55 / 39$ & $47 / 54$ & 0.09 \\
\hline $\begin{array}{l}\text { ADL score } \quad\left(n^{\circ} \quad \text { lost }\right. \\
\text { functions })\end{array}$ & $1.6(1.6)$ & $1.3(1.6)$ & 0.32 \\
\hline IADL score & $7.73(4.1)$ & $8.05(4.1)$ & 0.59 \\
\hline SPMSQ score & $2.5(2.3)$ & $2.35(2.6)$ & 0.06 \\
\hline CIRS Severity Index & $1.9(1.1)$ & $1.77(0.3)$ & 0.46 \\
\hline CIRS Comorbidity Index & $3.6(1.6)$ & $3.7(1.5)$ & 0.65 \\
\hline Baseline SBP $(\mathrm{mmHg})$ & $134.2(17.2)$ & $126.8(17.1)$ & $0.001^{*}$ \\
\hline Baseline DBP (mmHg) & $79.8(10.1)$ & $75.4(10.7)$ & $<0.001^{*}$ \\
\hline Baseline HR (beats/min) & $75.3(11.9)$ & $80.0(14.7)$ & $0.02^{*}$ \\
\hline HR 1' (beats/min) & $81.9(13.9)$ & $84.7(15.1)$ & 0.19 \\
\hline HR 3' (beats/min) & $79.3(15.8)$ & $83.8(15.2)$ & $0.05^{*}$ \\
\hline Number of drugs & $7.1(3.35)$ & $6.35(3.1)$ & 0.11 \\
\hline Cardiovascular disease & 91.2 & 82.8 & 0.08 \\
\hline Congestive heart failure & 5.9 & 6.5 & 0.87 \\
\hline Coronary artery disease & 32.4 & 18.3 & $0.02^{*}$ \\
\hline Hypertension & 79.4 & 73.1 & 0.3 \\
\hline Arrhythmia & 41.2 & 38.7 & 0.72 \\
\hline Valvular disease & 16.1 & 12.7 & 0.5 \\
\hline Neurological disease & 37.3 & 21.5 & $0.02^{*}$ \\
\hline TIA/Stroke & 5.9 & 3.2 & 0.38 \\
\hline Diabetes & 36.3 & 25.8 & 0.11 \\
\hline Previous syncope & 13.7 & 16.1 & 0.64 \\
\hline Previous fall & 33.3 & 36.5 & 0.64 \\
\hline
\end{tabular}

Table 1: Characteristics and co morbidities of the sample investigated, $\mathrm{OH}$ orthostatic hypotension, SBP systolic blood pressure, DBP diastolic blood pressure, HR hearth rate, TIA transient ischemic attack. ${ }^{\star}$ Variables reaching the step for significance set at $\mathrm{P}<0.05$, Booleans variables are reported in the table expressed as percentage

Prevalence of $\mathrm{OH}$ at entry was $52.3 \%$. At discharge it was not possible to perform the orthostatic test in 73 subjects who had been evaluated at admission: 55 were no more able to stand or keep the 
Page 3 of 5

upright position on their own, 6 were transferred to other wards, 6 were dead and 10 were not cooperating. Among the remaining 122 patients, prevalence of $\mathrm{OH}$ was $49 \%$. Subjects showing $\mathrm{OH}$ at baseline and at discharge were not systematically the same: $\mathrm{OH}$ was observed in both circumstances in 44 cases, 16 patients presented $\mathrm{OH}$ just at entry while 18 patients were diagnosed with $\mathrm{OH}$ at discharge only.

At baseline subjects with $\mathrm{OH}$ had higher systolic and diastolic blood pressure values $(\mathrm{p}=0.001, \mathrm{p}<0.001$, respectively) and showed a lower heart rate both at baseline and after 3 minutes of standing $(\mathrm{p}=0.02$, $\mathrm{p}=0.05$ ). Among all the clinical and multidimensional variables considered, including drug categories and classes of blood pressure lowering drugs (Table 1) $\mathrm{OH}$ was weakly associated only with history of coronary artery disease $(\mathrm{CAD} ; \mathrm{p}=0.02)$ and neurological disease $(\mathrm{p}=0.02)$. After multivariate adjustment these variables were independently associated with $\mathrm{OH}(\mathrm{p}=0.02, \mathrm{p}=0.03)$.

There was no difference in incidence of syncope, falls, length of stay and mortality between patients with and without $\mathrm{OH}$. The six-month Kaplan Meyer survival curves (Figure 1) did not show any difference between patients with and those without $\mathrm{OH}$, as well as there was no difference in the incidence of each adverse event between patients with and without $\mathrm{OH}$ (Table 2).

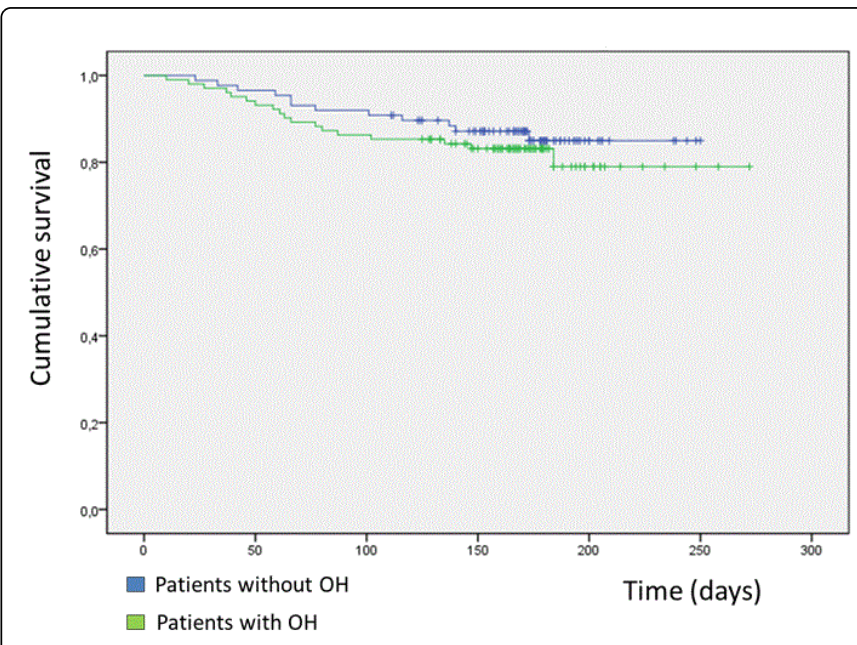

Figure 1: Kaplan-Meyer curves showing survivals six months after discharge, $\mathrm{OH}$ orthostatic hypotension

\begin{tabular}{|c|c|c|c|}
\hline Adverse events & With $\mathbf{O H}(\mathbf{n}=\mathbf{9 4})$ & Without $\mathbf{O H}(\mathbf{n = 8 0})$ & $\mathbf{P}$ Value \\
\hline Falls & 12 & 11 & 0.85 \\
\hline Syncope & 1 & - & 0.27 \\
\hline Fracture & 1 & 5 & 0.06 \\
\hline Hospitalization & 31 & 24 & 0.67 \\
\hline Institutionalization & 14 & 9 & 0.5 \\
\hline Myocardial infarction & 2 & 1 & 0.66 \\
\hline TIA/Stroke & - & 1 & 0.27 \\
\hline
\end{tabular}

Table 2: Adverse events considered six months after discharge, $\mathrm{OH}$ orthostatic hypotension, TIA transient ischemic attack

\section{Discussion}

Orthostatic hypotension is described as a common disorder in the elderly, particularly in the acute medical setting. We observed that about half of the older patients admitted to an acute Geriatric Ward were diagnosed with $\mathrm{OH}$ and therefore our results confirm the high prevalence of $\mathrm{OH}$ reported in those few other studies which investigated hospitalized elderly inpatients [16-18,27]. Despite a large and comprehensive evaluation, $\mathrm{OH}$ was found to be independently associated only with medical history of neurological disease (but not with stroke or transient ischemic attack) and CAD. Although this later observation may be a casual finding, a previous study among community-dwelling older subjects population reported that participants with $\mathrm{OH}$ were more likely to have a medical history of myocardial infarction [5]. Subjects with $\mathrm{OH}$ had higher systolic blood pressure values at baseline. Raised blood pressure values in patients affected by $\mathrm{OH}$ have been reported in previous studies either in community-dwelling, nursing-home population and in hospital inpatients $[4,6,8,9,12,17]$.

Although we performed a careful multidimensional evaluation we didn't find any association between $\mathrm{OH}$ and the several variables potentially involved in the pathogenesis of $\mathrm{OH}$. Moreover, the test repetition at discharge showed that $\mathrm{OH}$ is a not-reproducible disease. Therefore, it seems likely that in older acute medical inpatients several physiopathological factors and therapeutic measures can contribute to the pathogenesis of $\mathrm{OH}$ during the hospital stay. This complex interplay between physiopathological conditions and therapeutic variations makes extremely hard to analyze the potential impact on $\mathrm{OH}$ of variations in drug therapy between admission and discharge. Indeed, in the older patient acute events as well as therapeutic interventions can precipitate an already impaired compensatory response to standing. Age-related changes that can affect the normal blood pressure regulation in the elderly include decreased baroreflex sensitivity, alpha-1-adrenergic vasoconscrictor response, parasymphathetic activity and renal salt and water conservation, an increased vascular stiffness and a reduced left ventricular diastolic filling [36]. Many factors can influence $\mathrm{OH}$ development in the acute medical setting, mainly concerning causes of low circulating volume such as arrhythmia, myocardial infarction, acute heart failure, dehydration, diarrhea, vomiting, fever and hemorrhage. The resolution of the acute phase and a fluid volume expansion could lead to a restoration of the normal circulating volume with a more efficient compensatory response to standing. On the contrary prolonged bed rest can promote the development of the $\mathrm{OH}$. The genesis of the bed rest deconditioning involves multiple mechanisms. With the loss of the head-to-foot hydrostatic pressure gradient, the blood shift from the peripheral to the central veins increases the right and the left ventricular transmural pressure. After a transient increase in diastolic filling and stroke volume, the activation of the short-term regulatory volume mechanism results in the establishment of a new hemodynamic steady state, set to a lower circulating plasma volume. A ventricular remodelling over time during longer bed rest was also suggested to contribute to the $\mathrm{OH}$ development [37], as well as a decrease carotid-cardiac baroreflex [38]. During the stay in hospital, furthermore, a changing in or a revision of the pharmacological therapy can impair or improve the regulatory reflex to orthostatic stress. Nevertheless, other studies previously performed on an elderly outpatients' population find that $\mathrm{OH}$ is often a not-reproducible disease. On subsequent occasions in the morning, Ward et al monitored $\mathrm{OH}$ up to two minutes after standing in a sample of forty outpatients symptomatic for syncope, fall or postural symptoms. 
Orthostatic hypotension was confirmed only in the $67.5 \%$ of subjects on different occasions [39]. Similarly, in an Italian study performed on 3858 outpatients randomly recruited by general practitioners the $\mathrm{OH}$ presence on a second visit after seven days was confirmed in 36.5\% and in $25.7 \%$ of cases considering systolic $\mathrm{OH}$ and both systolic and diastolic $\mathrm{OH}$ [40]. Moreover the $\mathrm{OH}$ reproducibility seems to be low over time the same day [16].

We did not observe a greater incidence of adverse events among patients with $\mathrm{OH}$ than in those without either during the hospital stay and at the follow up. These findings are consistent with the results of a long term follow up (until 3.5 years after discharge) on a sample of 502 elderly inpatients, with no evidence of association with $\mathrm{OH}$ and allcause mortality [26]. To our knowledge there are no other prospective data on elderly inpatients in an acute care setting. Although potentially of clinical utility and interest for selected older patients, our study adds to the evidence that the evaluation of $\mathrm{OH}$ is not predictive of adverse outcomes in short and medium terms in this setting of frail and vulnerable medical older patients. Therefore these results raise some doubts about the clinical utility of a routine investigation for $\mathrm{OH}$ among elderly medical inpatients. Recently, new evidence on $\mathrm{OH}$ from unselected older general population cohorts question whether, even in that contest, $\mathrm{OH}$ should be considered a real cardiovascular risk factor [9].

This study has several strengths. First it is an observationalprospective study. Second, the patients underwent a full comprehensive geriatric assessment and results were controlled for a great number of confounders. Finally the entire patient evaluation was performed by qualified medical staff. The present study has also some limitations. Our sample size wasn't very large and the number of the adverse events considered was small, which could have impaired our statistical analysis.

\section{Conclusion}

This study showed a high prevalence of $\mathrm{OH}$ among elderly medical inpatients, which was not systematically present in the same patients either at admission or at discharge. Moreover we could not find any association between clinical variables and $\mathrm{OH}$, as well as between the presence of $\mathrm{OH}$ and adverse outcomes either during the hospital stay or after discharge. Our findings raise some doubts about the utility to look for $\mathrm{OH}$ routinely in all older medical hospital inpatients. More studies on larger clinical samples are needed to confirm the clinical significance of $\mathrm{OH}$ among older patients.

\section{References}

1. Kaufmann H (1996) Consensus statement on the definition of orthostatic hypotension, pure autonomic failure and multiple system atrophy. Clin Auton Res 6: 125-126.

2. Masaki KH, Schatz IJ, Burchfiel CM, Sharp DS, Chiu D, et al. (1998) Orthostatic hypotension predicts mortality in elderly men: the Honolulu Heart Program. Circulation 98: 2290-2295.

3. Mader SL, Josephson KR, Rubenstein LZ (1987) Low prevalence of postural hypotension among community-dwelling elderly. JAMA 258: 1511-1514.

4. Verwoert GC, Mattace-Raso FU, Hofman A, Heeringa J, Stricker BH, et al. (2008) Orthostatic hypotension and risk of cardiovascular disease in elderly people: the Rotterdam study. J Am Geriatr Soc 56: 1816-1820.

5. Rutan GH, Hermanson B, Bild DE, Kittner SJ, LaBaw F, et al. (1992) Orthostatic hypotension in older adults. The Cardiovascular Health Study. CHS Collaborative Research Group. Hypertension 19: 508-519.
6. Räihä I, Luutonen S, Piha J, Seppänen A, Toikka T, et al. (1995) Prevalence, predisposing factors, and prognostic importance of postural hypotension. Arch Intern Med 155: 930-935.

7. Luukinen H, Koski K, Laippala P, Kivelä SL (1999) Prognosis of diastolic and systolic orthostatic hypotension in older persons. Arch Intern Med 159: 273-280.

8. Kamaruzzaman S, Watt H, Carson C, Ebrahim S (2010) The association between orthostatic hypotension and medication use in the British Women's Heart and Health Study. Age Ageing 39: 51-56.

9. Casiglia E, Tikhonoff V, Caffi S, Boschetti G, Giordano N, et al. (2014) Orthostatic hypotension does not increase cardiovascular risk in the elderly at a population level. Am J Hypertens 27: 81-88.

10. Fagard RH, De Cort P (2010) Orthostatic hypotension is a more robust predictor of cardiovascular events than nighttime reverse dipping in elderly. Hypertension 56: 56-61.

11. Alagiakrishnan K, Patel K, Desai RV, Ahmed MB, Fonarow GC, et al. (2014) Orthostatic hypotension and incident heart failure in communitydwelling older adults. J Gerontol A Biol Sci Med Sci 69: 223-230.

12. Low PA (2008) Prevalence of orthostatic hypotension. Clin Auton Res 18 Suppl 1: 8-13.

13. Valbusa F, Labat C, Salvi P, Vivian ME, Hanon O, et al. (2012) Orthostatic hypotension in very old individuals living in nursing homes: the PARTAGE study. J Hypertens 30: 53-60.

14. Hossain M, Ooi WL, Lipsitz LA (2001) Intra-individual postural blood pressure variability and stroke in elderly nursing home residents. J Clin Epidemiol 54: 488-494.

15. Shibao C, Grijalva CG, Raj SR, Biaggioni I, Griffin MR (2007) Orthostatic hypotension-related hospitalizations in the United States. Am J Med 120: 975-980.

16. Weiss A, Grossman E, Beloosesky Y, Grinblat J (2002) Orthostatic hypotension in acute geriatric ward: is it a consistent finding? Arch Intern Med 162: 2369-2374.

17. Poon IO, Braun U (2005) High prevalence of orthostatic hypotension and its correlation with potentially causative medications among elderly veterans. J Clin Pharm Ther 30: 173-178.

18. Gorelik O, Fishlev G, Litvinov V, Almoznino-Sarafian D, Alon I, et al. (2005) First morning standing up may be risky in acutely ill older inpatients. Blood Press 14: 139-143.

19. Luukinen H, Airaksinen KE (2005) Orthostatic hypotension predicts vascular death in older diabetic patients. Diabetes Res Clin Pract 67: 163-166.

20. Luukinen H, Koski K, Laippala P, Airaksinen KE (2004) Orthostatic hypotension and the risk of myocardial infarction in the home-dwelling elderly. J Intern Med 255: 486-493.

21. Luukinen H, Koski K, Laippala P, Kivelä SL (1999) Prognosis of diastolic and systolic orthostatic hypotension in older persons. Arch Intern Med 159: 273-280.

22. Ooi WL, Hossain M, Lipsitz LA (2000) The association between orthostatic hypotension and recurrent falls in nursing home residents. Am J Med 108: 106-111.

23. Lagro J, Laurenssen NC, Schalk BW, Schoon Y, Claassen JA, et al. (2012) Diastolic blood pressure drop after standing as a clinical sign for increased mortality in older falls clinic patients. J Hypertens 30: 1195-1202.

24. Tilvis RS, Hakala SM, Valvanne J, Erkinjuntti T (1996) Postural hypotension and dizziness in a general aged population: a four-year follow-up of the Helsinki Aging Study. J Am Geriatr Soc 44: 809-814.

25. Gangavati A, Hajjar I, Quach L, Jones RN, Kiely DK, et al. (2011) Hypertension, orthostatic hypotension, and the risk of falls in a community-dwelling elderly population: the maintenance of balance, independent living, intellect, and zest in the elderly of Boston study. J Am Geriatr Soc 59: 383-389.

26. Weiss A, Beloosesky Y, Kornowski R, Yalov A, Grinblat J, et al. (2006) Influence of orthostatic hypotension on mortality among patients discharged from an acute geriatric ward. J Gen Intern Med 21: 602-606. 
Citation: Tibaldi M, Brescianini A, Sciarrillo I, Massaia M, Bo M (2014) Prevalence and Clinical Implications of Orthostatic Hypotension in Elderly Inpatients. J Hypertens 3: 155. doi:10.4172/2167-1095.1000155

Page 5 of 5

27. Romero-Ortuno R, Cogan L, O'Shea D, Lawlor BA, Kenny RA (2011) Orthostatic haemodynamics may be impaired in frailty. Age Ageing 40: 576-583.

28. Mancia G, De Backer G, Dominiczak A, Cifkova R, Fagard R, et al. (2007) 2007 Guidelines for the management of arterial hypertension: The Task Force for the Management of Arterial Hypertension of the European Society of Hypertension (ESH) and of the European Society of Cardiology (ESC). Eur Heart J 28: 1462-1536.

29. Wieling W, Schatz IJ (2009) The consensus statement on the definition of orthostatic hypotension: a revisit after 13 years. J Hypertens 27: 935-938.

30. Lahrmann H, Cortelli P, Hilz M, Mathias CJ, Struhal W, et al. (2006) EFNS guidelines on the diagnosis and management of orthostatic hypotension. Eur J Neurol 13: 930-936.

31. Parmelee PA, Thuras PD, Katz IR, Lawton MP (1995) Validation of the Cumulative Illness Rating Scale in a geriatric residential population. J Am Geriatr Soc 43: 130-137.

32. Pfeiffer E (1975) A short portable mental status questionnaire for the assessment of organic brain deficit in elderly patients. J Am Geriatr Soc 23: 433-441.

33. Katz S, Downs TD, Cash HR, Grotz RC (1970) Progress in development of the index of ADL. Gerontologist 10: 20-30.
34. Lawton MP, Brody EM (1969) Assessment of older people: selfmaintaining and instrumental activities of daily living. Gerontologist 9: 179-186.

35. Podsiadlo D, Richardson S (1991) The timed "Up \& Go": a test of basic functional mobility for frail elderly persons. J Am Geriatric Soc 39: $142-148$.

36. Gupta V, Lipsitz LA (2007) Orthostatic hypotension in the elderly: diagnosis and treatment. Am J Med 120: 841-847.

37. Perhonen MA, Zuckerman JH, Levine BD (2001) Deterioration of left ventricular chamber performance after bed rest : "cardiovascular deconditioning" or hypovolemia? Circulation 103: 1851-1857.

38. Ertl AC, Diedrich A, Biaggioni I (2000) Baroreflex dysfunction induced by microgravity: potential relevance to postflight orthostatic intolerance. Clin Auton Res 10: 269-277.

39. Ward C, Kenny RA (1996) Reproducibility of orthostatic hypotension in symptomatic elderly. Am J Med 100: 418-422.

40. Alli C, Avanzini F, Bettelli G, Colombo F, Corso R, et al. (1992) Prevalence and variability of orthostatic hypotension in the elderly. Results of the 'Italian study on blood pressure in the elderly (SPAA)'. The 'Gruppo di Studio Sulla Pressione Arteriosa nell'Anziano'. Eur Heart J 13: 178-182. 